\title{
DESENVOLVIMENTO HIDROLÓGICO E FENOLOGIA DE LAGOS DA PENÍNSULA FILDES - ANTÁRTICA
}

\author{
HYDROLOGICAL DEVELOPMENT AND PHENOLOGY OF LAKES OF THE FILDES \\ PENINSULA - ANTARCTICA
}

\author{
Carina PETSCH ${ }^{1,2}$, Rafaela Mattos COSTA ${ }^{2}$, Kátia Kellem da ROSA ${ }^{2}$, Rosemary \\ VIEIRA $^{3}$, Matthias Holger BRAUN ${ }^{4}$, Jefferson Cardia SIMÕES ${ }^{2}$ \\ ${ }^{1}$ Universidade Federal de Santa Maria- UFSM. Departamento de Geociências. Avenida Roraima, 1000. Santa Maria - RS, Brasil. \\ E-mail: carinapetsch@gmail.com \\ ${ }^{2}$ Universidade Federal do Rio Grande do Sul, Centro Polar e Climático. Av. Bento Gonçalves, 9.500, Porto Alegre -RS. \\ E-mails: raffaellamattos@hotmail.com; katiakellem@gmail.com; jefferson.simoes@ufrgs.br \\ ${ }^{3}$ Universidade Federal Fluminense, Instituto de Geociências. Av. Milton Tavares de Souza, s/nº, Niterói - RJ. \\ E-mail: rosemaryvieira@id.uff.br \\ ${ }^{4}$ Universidade Friedrich Alexander. Instituto de Geografia. Wetterkreuz, 15. Erlangen. Alemanha. \\ E-mail: matthias.h.braunn@fau.de

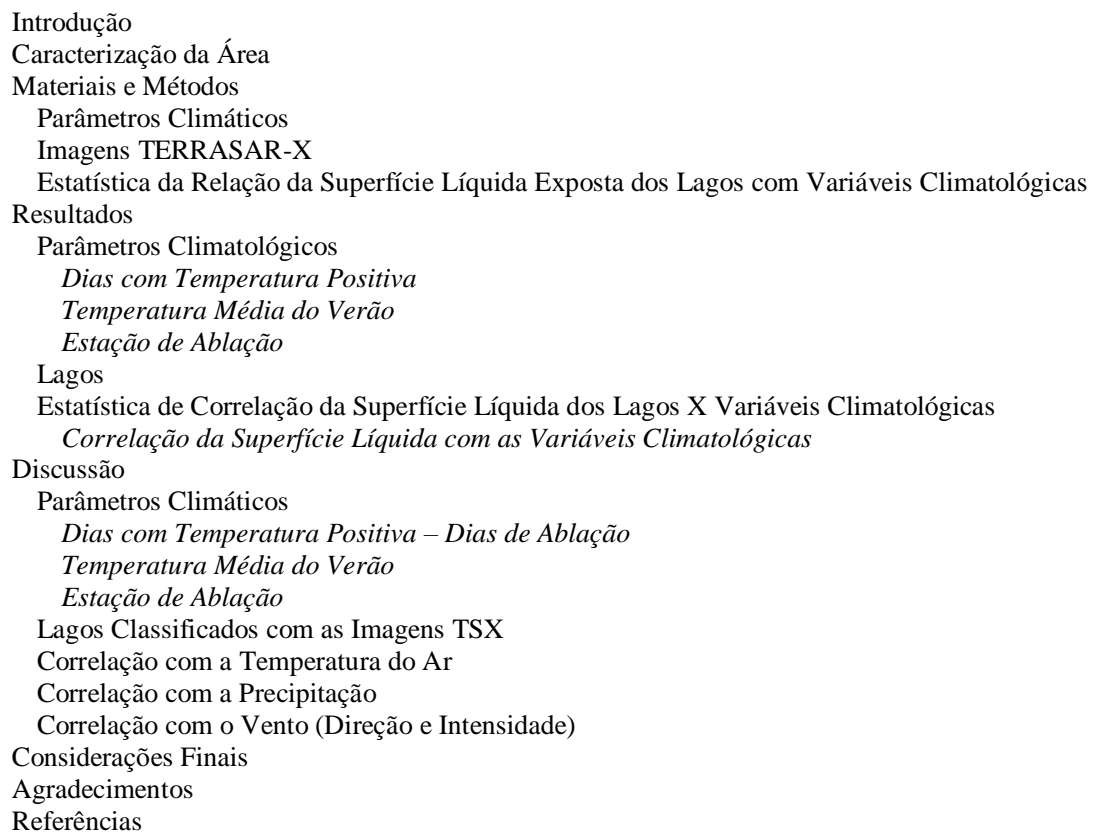

RESUMO - Este artigo avalia a dinâmica de congelamento e descongelamento dos lagos da península Fildes, utilizando imagens TerraSAR-X (TSX) entre fevereiro e abril de 2011, e a correlação da área de superfície líquida com as variáveis temperatura, precipitação e vento. A área de superfície líquida foi obtida a partir de classificação de imagem TSX, utilizando o classificador MAXVER, para 12 imagens do ano de 2011. A correlação de temperatura do ar atmosférico com a área, determinada pelo método de correlação de Spearman e Pearson, demonstra padrão de correlação significativa em 7 dos 15 lagos, enquanto a precipitação é uma importante variável na formação da superfície líquida em 11 dos 15 lagos. Todos os lagos voltados para a passagem de Drake mostram correlação significativa com a direção do vento que atua causando ondas na superfície líquida e que, por sua vez, provocam a quebra do gelo na superfície. Quanto à direção dos ventos, esta variável pode estar ligada à mudanças na duração do período de ablação para a península Fildes. De forma geral, as imagens TSX permitiram um detalhamento temporal inédito para a área de estudo, possibilitando mapear os lagos no período entre fevereiro e abril de 2011.

Palavras-chave: glaciologia; lagos glaciais; Antártica.

\begin{abstract}
This paper evaluates the freezing and thawing dynamics of the Fildes Peninsula lakes using TerraSAR-X (TSX) images from February to April 2011, and the correlation of the open water surface area with temperature, precipitation and wind. The open water surface area was obtained from the TSX images classification using the MAXVER classifier for 12 images from 2011. The correlation of atmospheric air temperature with the area, determined by the Pearson and Spearman correlation method, demonstrates a significant correlation pattern in 7 of the 15 lakes, while precipitation is an important variable for the formation of open water in 11 of the 15 lakes. All lakes facing the Drake Passage show significant correlation with wind direction. It is possible that the wind acts causing waves on the liquid surface, which in turn cause the surface ice to break. As for wind direction, this variable may be linked to changes in the duration of the ablation period for the Fildes peninsula. In general, the TSX images allowed an unprecedented temporal detailing for the study area, making it possible to map the lakes from February to April 2011.
\end{abstract}

Keywords: glaciology; glacial lakes; Antarctica. 


\section{INTRODUÇÃO}

Mudanças na cobertura de neve, na posição da frente das geleiras e no volume de gelo são claros exemplos de indicadores de mudanças climáticas que afetam o sistema hidrológico proglacial (Quesada et al., 2006; Latifovic \& Pouliot, 2007; Adrian et al., 2009) e que irão diretamente afetar os lagos glaciais em áreas livres de gelo no verão (Duguay et al., 2006; Šmejkalová et al., 2016). Na Antártica, os lagos são encontrados principalmente em regiões costeiras (Doran et al., 1994).

A formação de gelo na superfície dos lagos é diretamente afetada pela temperatura do ar, no entanto, há outras variáveis que interferem como padrões de acumulação de neve e derretimento na proximidade, precipitação, condições do vento, localização (latitude e características da paisagem), elevação e variáveis morfológicas (tamanho do lago e profundidade) (Williams, 1971; Palecki \& Barry, 1986; Vavrus et al., 1996; Menard et al., 2002; Śmejkalová et al., 2016).

A fenologia da cobertura de gelo, que é a dinâmica de congelamento e descongelamento da superfície, pode afetar e controlar o período de crescimento, interações químicas entre água e atmosfera, e características hidrológicas dos lagos (Austin \& Colman, 2007) e também influencia na biologia e biogeoquímica (Quayle et al., 2002; Blenckner, 2005; Williamson et al. 2009).

Além disso, a transferência direta de calor entre lagos e a atmosfera aumenta o tempo que esses atuam como fonte de gases de efeito estufa devido a processos químicos e biológicos, o que aumenta também a evaporação anual da superfície do lago (Latifovic \& Pouliot, 2007). Salienta-se que para a península Fildes, estudos de fenologia de lagos ainda não foram realizados.

Para a Antártica os estudos encontrados concentram-se na medida de nível de água dos lagos em uma série histórica. Castendyk et al. (2016) observaram que o lago Vanda, localizado nos Vales Secos em McMurdo (Antártica Ocidental), apresentou um aumento de $15 \mathrm{~m}$ no seu nível de água ao longo dos últimos 68 anos em resposta à variabilidade do clima e descarga anual do rio Onyx, sua principal fonte de água.

A ilha subantártica Signy $\left(60^{\circ} 43^{\prime} \mathrm{S}\right)$ possui 17 lagos que representam os registros lacustres contínuos mais longos da Antártica (Quayle et al., 2002).

Os padrões hidrológicos nessa ilha indicam aumento de água dos lagos e canais glacio fluviais no final do verão, cada vez mais influenciados pela precipitação direta líquida, em vez da ablação de neve ou derretimento de gelo da geleira (Noon et al., 2002)

Quanto ao monitoramento constante de lagos proglaciais, salienta-se que o alto custo e logística restringem as viagens de pesquisa para as regiões polares.

Nesse sentido, o uso do Sensoriamento Remoto permite o monitoramento da cobertura de gelo de um grande número de lagos em uma grande área (Pierson et al., 2011).

Sensores ópticos como MODIS, GOESVISSR, AVHRR e SPOT-VEGETATION têm sido utilizados para estimar o início do descongelamento baseado na interpretação visual das imagens (Jeffries et al., 2005; Latifovic \& Pouliot, 2007). Contudo a alta presença de nuvens na região das ilhas Shetland do Sul não permite uma cobertura de imagens ópticas adequada para monitoramento.

Uma solução para realizar o mapeamento de lagos e eventos de congelamento e descongelamento é utilizar os dados de Radar de Abertura Sintética - SAR (Jeffreis et al., 1994; Duguay \& Lafleur, 1997; Baghdadi et al., 2001) que permitem imageamento independente da presença de nebulosidade

O presente artigo avalia a dinâmica de congelamento e descongelamento dos lagos da península Fildes, utilizando imagens TerraSARX entre fevereiro e abril de 2011, e a correlação da variação da área de superfície líquida com as variáveis temperatura, precipitação e vento.

Afim de caracterizar a série histórica de dados climatológicos e verificar quanto o ano de 2011 representa condições próximas dos demais anos, foram realizados cálculos de temperatura média do verão, número de dias com temperatura positiva e duração da estação de ablação para os meses de janeiro a abril.

\section{CARACTERIZAÇÃo dA ÁREA}

A península Fildes (Figura 1), localiza-se na pequeno domo de gelo, a geleira Collins (Figura 1), parte sul da ilha Rei George $\left(62^{\circ} 08^{\prime}\right.$ e $62^{\circ} 14 ' \mathrm{~S}$; $59^{\circ} 02^{\prime}$ e $\left.58^{\circ} 51^{\prime} \mathrm{O}\right)$, é limitada a nordeste por um aproximadamente na latitude $62^{\circ} 12^{\prime} \mathrm{S}$ e longitude $58^{\circ} 57^{\prime} \mathrm{O}$, com uma área de $15 \mathrm{~km}^{2}$ e elevação 
máxima de 270 m (Simões et al., 2015).

Rosa et al. (2015) mostram que o processo de retração da geleira produz distintos ambientes na parte norte da península Fildes, com fluxos de fusão provenientes da geleira, originando lagos e alagados com dois tipos de drenagens: um interno e outro voltado para a enseada Maxwell. Os processos geomorfológicos que ocorrem atualmente na Península Fildes são nivação, solifluxão, ablação e erosão e crioturbação (Simas et al., 2008).

De acordo com Michel et al. (2014), os solos da Península Fildes são bem desenvolvidos para padrões antárticos, sendo os criossolos dominantes relacionados a crioturbação e processos da camada ativa. Os processos periglaciais são dominantes em altitudes acima de $50 \mathrm{~m}$ onde são comuns solos em padrão.

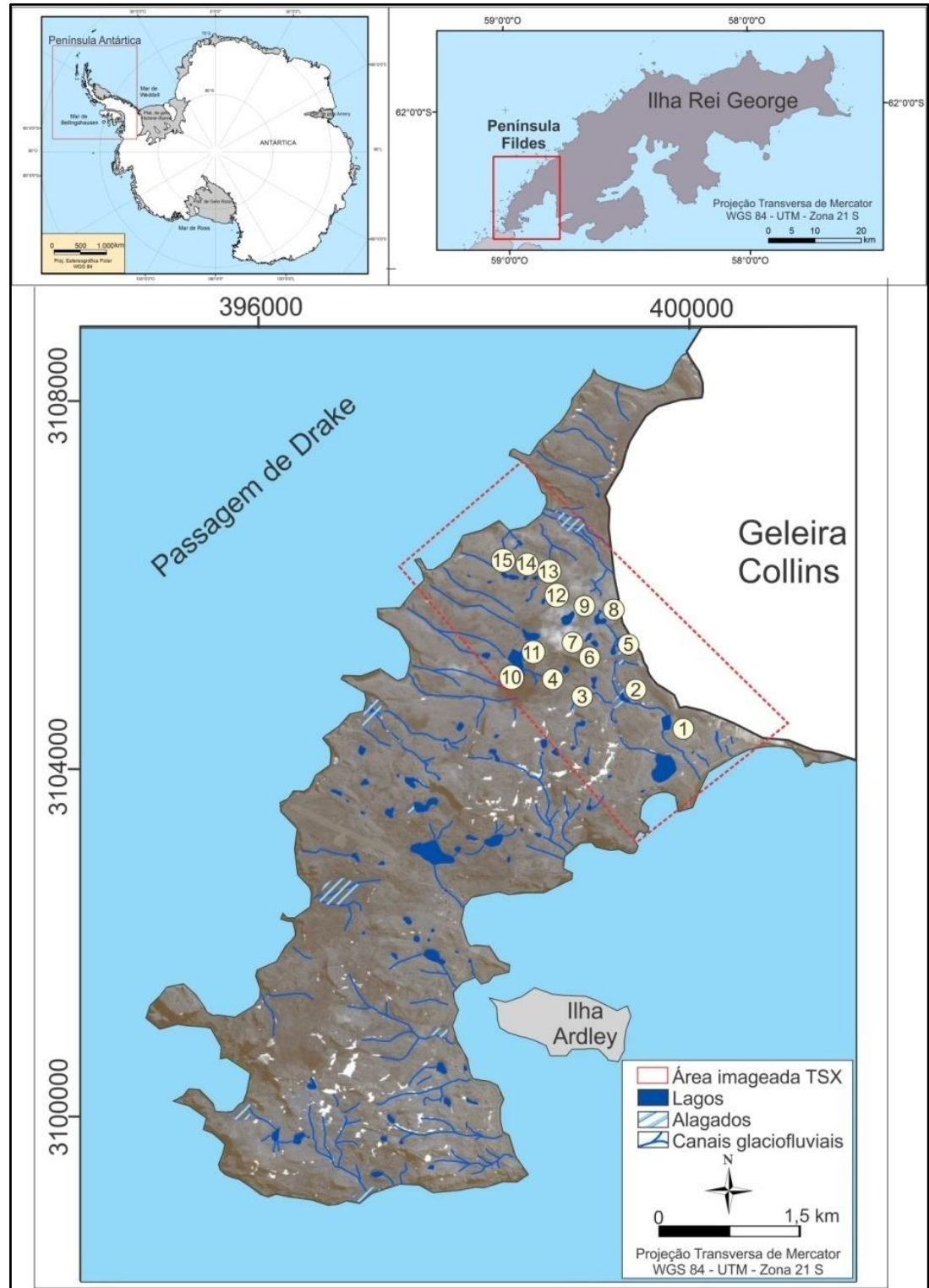

Figura 1 - A) Os números de 1 a 15 referem-se aos lagos estudados nesse estudo e classificados em 3 ambientes: "proglaciais, menores e Drake".

A vegetação na ilha Rei George é composta basicamente por tundras mal desenvolvidas e consistem quase exclusivamente em criptógamas, líquens e musgos (Olech, 2001). Já o clima caracteriza-se pela frequente sucessão de centros de baixa pressão móveis a leste na zona circumpolar do vento oeste do Hemisfério Sul (Turner \& Leonard, 1996). A localização da ilha tão próxima do mar faz com que durante o inverno ocorra um clima marítimo relativamente quente, resultando em baixa variabilidade anual das temperaturas mensais médias do ar (Smith et al., 1996).

Nos últimos 30 anos identificou-se na Ilha Rei George um aumento do número de dias por ano com precipitação líquida e de dias em que a temperatura média é maior do que $0^{\circ} \mathrm{C}$, o que influencia diretamente no aumento do derretimento de neve e gelo das geleiras da ilha (Braun et al., 2001; Ferrando et al., 2009). 


\section{MATERIAIS E MÉTODOS}

\section{Parâmetros Climáticos}

Foram aplicados parâmetros climáticos (Tabela 1) para verificar a temperatura média do verão (janeiro-março), número de dias com precipitação positiva (janeiro, fevereiro, março e abril) e a duração da estação da ablação (janeiro-abril) para a série histórica de dados para a área (1977-2017), obtidos na estação da pista de pouso Eduardo Frei
Montalva (62¹1'40”S; 58०58'25”O).

\section{Imagens TERRASAR-X}

A área de estudo foi recortada e delimitada de acordo com a área contemplada pelas imagens TSX, para a península Fildes (Figura 1).

As imagens do sensor TSX (Tabela 2) foram obtidas no formato SSC (Single Look Slant Range Complex), entre 1 de fevereiro e 19 de abril de 2011.

Tabela 1 - Parâmetros climáticos utilizados para o período de 1977-2017.

\begin{tabular}{c|c|c}
\hline Parâmetro & Cálculo & Referências \\
\hline $\begin{array}{c}\text { Temperatura média } \\
\text { do verão }\end{array}$ & $\Sigma$ Temperatura diária (verão) / Número de dias & Hanson $(1987)$ \\
\hline $\begin{array}{c}\text { Número de dias com } \\
\text { temperatura positiva }\end{array}$ & $\Sigma$ Temperatura média diária com temperatura $>0{ }^{\circ} \mathrm{C}$ & $\begin{array}{c}\text { Orheim }(1972), \text { Bradley } \\
\& \text { England }(1978)\end{array}$ \\
\hline $\begin{array}{c}\text { Duração da estação de } \\
\text { ablação }\end{array}$ & $\begin{array}{c}\text { Número de dias entre os três primeiros dias } \\
\text { consecutivos com } \mathrm{T}>0{ }^{\circ} \mathrm{C}, \text { na primavera, e os três } \\
\text { últimos dias consecutivos com } \mathrm{T}>00^{\circ} \mathrm{C}, \text { no outono. }\end{array}$ & $\begin{array}{c}\text { Bradley \& England } \\
(1978)\end{array}$ \\
\hline
\end{tabular}

Tabela 2 - Imagens TSX utilizadas para classificação da superfície dos lagos.

\begin{tabular}{|c|c|c|c|c|c|c|}
\hline Data & $\begin{array}{l}\text { Tipo de } \\
\text { produto }\end{array}$ & $\begin{array}{c}\text { Modo da } \\
\text { imagem }\end{array}$ & Polarização & $\begin{array}{c}\text { Direção de } \\
\text { passada }\end{array}$ & $\begin{array}{c}\text { Canais de } \\
\text { polarização }\end{array}$ & $\begin{array}{c}\text { Resolução } \\
\text { espacial (m) }\end{array}$ \\
\hline $01 / 02 / 2011$ & SSC & SM & $S$ & Ascendente & $\mathrm{HH}$ & 3 \\
\hline $12 / 02 / 2011$ & SSC & SM & $S$ & Ascendente & $\mathrm{HH}$ & 3 \\
\hline $23 / 02 / 2011$ & $\mathrm{SSC}$ & SM & $S$ & Ascendente & $\mathrm{HH}$ & 3 \\
\hline 28/02/2011 & SSC & HS & $S$ & Ascendente & $\mathrm{HH}$ & 1 \\
\hline $01 / 03 / 2011$ & $\mathrm{SSC}$ & HS & $S$ & Descendente & $\mathrm{HH}$ & 1 \\
\hline $06 / 03 / 2011$ & SSC & SM & $S$ & Ascendente & $\mathrm{HH}$ & 3 \\
\hline $11 / 03 / 2001$ & SSC & HS & S & Ascendente & $\mathrm{HH}$ & 1 \\
\hline $12 / 03 / 2011$ & SSC & HS & S & Descendente & $\mathrm{HH}$ & 1 \\
\hline $17 / 03 / 2011$ & $\mathrm{SSC}$ & SM & S & Ascendente & $\mathrm{HH}$ & 3 \\
\hline 28/03/2011 & $\mathrm{SSC}$ & SM & S & Ascendente & $\mathrm{HH}$ & 3 \\
\hline $08 / 04 / 2011$ & SSC & SM & S & Ascendente & $\mathrm{HH}$ & 3 \\
\hline $19 / 04 / 2011$ & SSC & SM & S & Ascendente & $\mathrm{HH}$ & 3 \\
\hline
\end{tabular}

A sequência de processamento das imagens (Figura 2) foi realizada de acordo com os métodos de Badurska (2011) e Gorrab et al. (2015), sendo que primeiramente os produtos TSX-SSC, com valores dos dados em radiância, foram transformados em multilook; após essa etapa foram calibrados radiometricamente para obter o coeficiente de retroespalhamento, para corrigir diferenças causadas pela topografia do terreno, e os valores dos pixels transformados para Sigma; então foram corrigidas geometricamente usando o Modelo Digital de Elevação (MDE) Getasse no software SNAP; por fim, foi realizada a transformação para valores em dB (decibéis) e aplicação do filtro de mediana, janela 5x5, para redução do speckle (ruídos nas imagens).

Após testes realizados com classificadores supervisionados e não supervisionados, os melhores resultados para classificação das imagens foram obtidos com o classificador de Máxima Verrosimilhança (MAXVER).

Para o treinamento das amostras foram delimitados polígonos dos seguintes alvos: água líquida, água congelada, área com neve e área livre de neve. 


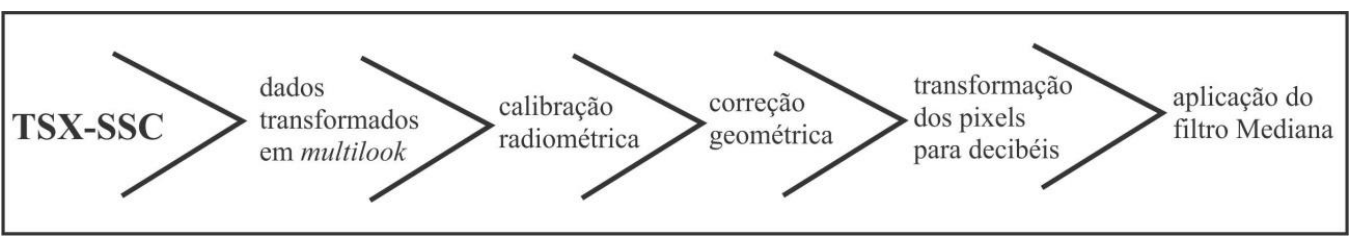

Figura 2 - Sequência de processamento das imagens TerraSAR X.

Estatística da Relação da Superfície Líquida Exposta dos Lagos com Variáveis Climatológicas

A metodologia foi baseada em Kropacek et al. (2013) que aplicou o coeficiente de correlação entre a área de superfície líquida de lagos com variáveis climatológicas locais. Para tanto, foi realizado o teste estatístico de KolmogorovSmirnov para verificar a normalidade das variáveis climatológicas, utilizando o software OriginPro 2017. As hipóteses do teste são: $\mathrm{H}_{0}$; a variável tem distribuição normal e $\mathrm{H}_{1}$ : a variável não tem distribuição normal. Para esta pesquisa foram adotados os valores acima de 0,4 e abaixo de $-0,4$ como de correlação aceitável. Para dados não paramétricos foi utilizado a correlação de Spearman e para dados paramétricos, a de Pearson considerando um valor de significância ( $\rho$ ) de 0,05 .

O índice de correlação foi calculado a partir das medianas das variáveis climatológicas (temperatura, velocidade e direção do vento) dos últimos 10 dias com a área de superfície líquida dos lagos, para as datas em que há imagens TSX (Tabela 2). Para a variável de precipitação foi considerado o acumulado, ou seja, a soma dos valores registrados nos últimos 10 dias. Os dados de área de superfície líquida foram transformados em percentuais para questão de normalização.

\section{RESULTADOS}

\section{Parâmetros Climatológicos}

Primeiramente, serão caracterizados os valores de parâmetros climatológicos para a série histórica (1977-2017) afim de caracterizar a temperatura média do verão, número de dias com temperatura positiva e duração da estação de ablação para os meses de janeiro a abril, pois é o período em que as imagens TSX estão disponíveis. É importante compreender como o ano de 2011 se encaixa na variação desses dados climatológicos em escala temporal.

\section{Dias com Temperatura Positiva}

Considerando a série histórica de dados de temperatura (1977-2017), o mês de janeiro apresenta uma média de 26, 29, 29 e 27 dias com temperatura positiva para as décadas de 19771987, 1987-1997, 1997-2007, 2007-2017, respectivamente; para o mês de fevereiro os valores são de 25, 25, 26, 22 dias para as décadas acima analisadas; para o mês de março os valores são de 19, 18, 19 e 20 dias para as décadas citadas; para abril são de 12, 8, 10 e 4 dias. Os dias de temperatura positiva em 2011 registram a marca de 27 dias para janeiro, 28 para fevereiro (todo o mês), 18 para março e 2 dias para abril (Figura 3).

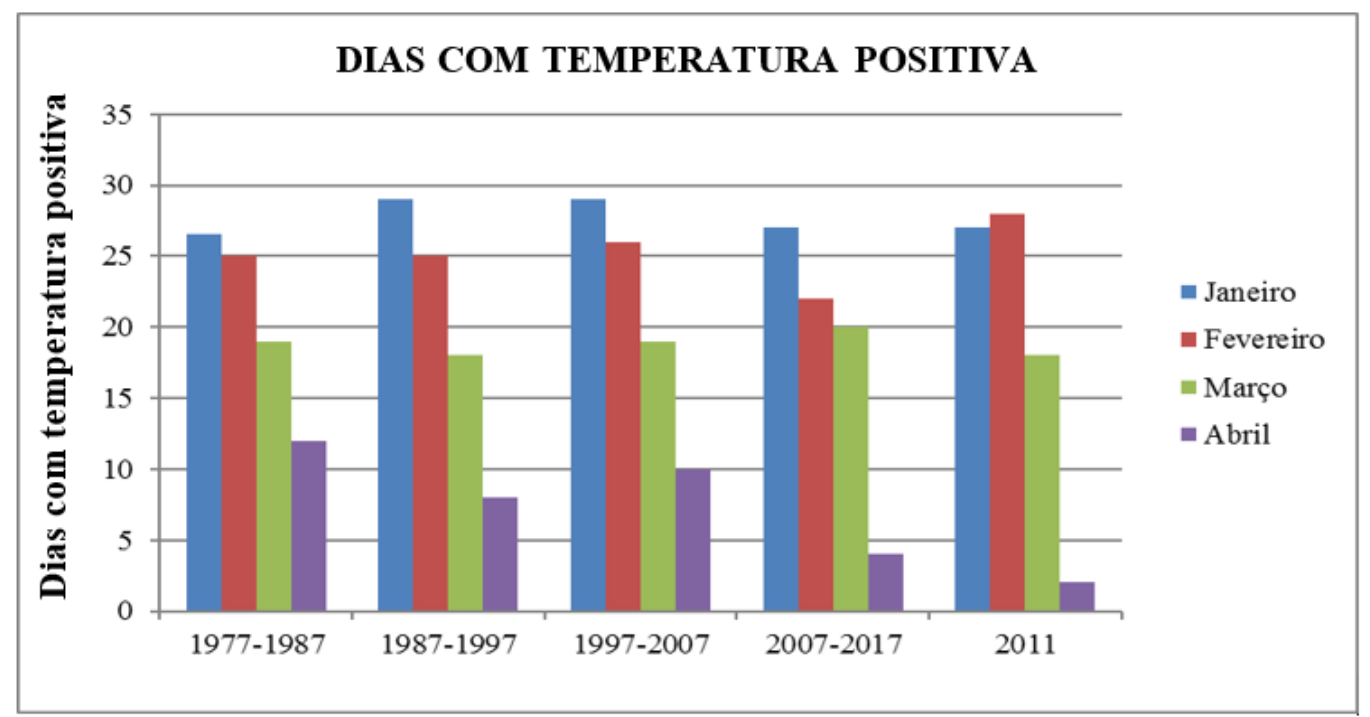

Figura 3 - Dias com temperatura acima de $0{ }^{\circ} \mathrm{C}$. É possível notar uma diminuição para o mês de abril e um aumento para o mês de março, a partir de 1987.

São Paulo, UNESP, Geociências, v. 39, n. 2, p. 559 - 572, 2020 


\section{Temperatura Média do Verão}

$\mathrm{O}$ índice de temperatura média do verão mostra que para o mês de janeiro valores foram de $1,40^{\circ} \mathrm{C}, 1,70^{\circ} \mathrm{C}, 1,55^{\circ} \mathrm{C}$ e $0,93^{\circ} \mathrm{C}$ para as décadas analisadas de 1977-1987, 1987-1997, 1997-2007 e 2007-2017, respectivamente. Para o mês de fevereiro os valores oscilam entre $1,48^{\circ} \mathrm{C}, 1,75^{\circ} \mathrm{C}, 1,60^{\circ} \mathrm{C}$ e $1,02^{\circ} \mathrm{C}$ para as décadas acima citadas; para o mês de março os valores foram de $0,60^{\circ} \mathrm{C}, 0,36^{\circ} \mathrm{C}, 0,53^{\circ} \mathrm{C}$ e $0,40^{\circ} \mathrm{C}$ para as décadas analisadas.

$\mathrm{O}$ ano de 2011 mostra valores de $0,93^{\circ} \mathrm{C}$, $1,97^{\circ} \mathrm{C}$ e $0,27^{\circ} \mathrm{C}$ para janeiro, fevereiro e março, respec-tivamente (Figura 4).

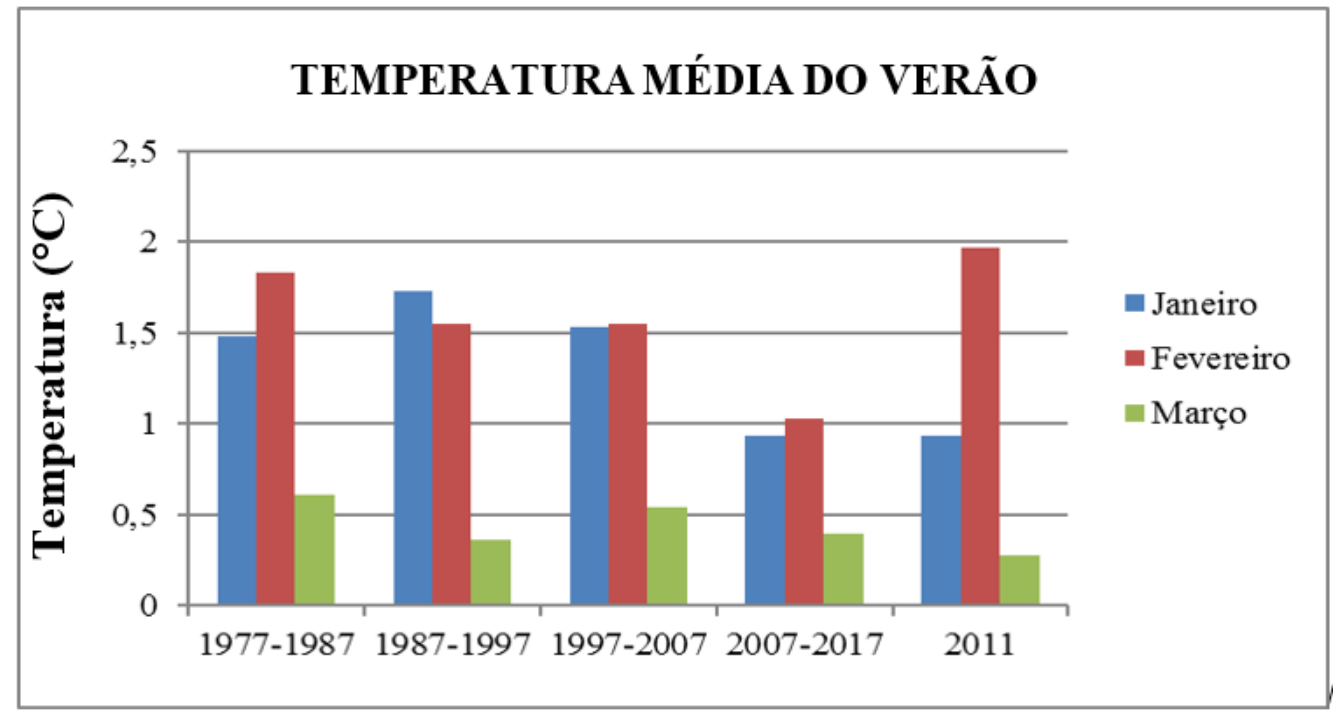

Figura 4 - Temperatura média dos meses de janeiro, fevereiro e março.

\section{Estação de Ablação}

Considerando a série temporal analisada (19772017), em somente dez anos o último dia de ablação aconteceu em março e em 30 anos foi em abril.

Na década de 1977-1987 a estação de ablação durou 138 dias; para 1987-1997 durou 127 dias; para 1997-2007 foi de 129 dias e para a década de 2007-2017 foi de 119 dias, enquanto que para 2011 foi somente de 90 dias

\section{Lagos}

Os 15 lagos analisados nesta pesquisa foram divididos em três grupos (Tabela 3), segundo critérios de localização, tamanho e presença de canais de degelo provenientes da geleira. Sendo assim, todos os lagos que recebiam água de derretimento da geleira, por meio de canais, foram nomeados de proglaciais (lagos 1, 2, 5 e 8); todos os lagos com área menor que $3957 \mathrm{~m}^{2} \mathrm{e}$ localizados na porção central na área proglacial da geleira Collins foram classificados como "menores"; e, todos os lagos próximos da Passagem de Drake (menos de $2 \mathrm{~km}$ da costa) foram nomeados como sendo "Drake" (lagos 10, $11,12,13,14$ e 15$)$.

A classificação das imagens TSX (fevereiroabril de 2011) foi realizada para os alvos: água congelada, água líquida e área com cobertura de neve e sem cobertura de neve:
Tabela 3 - Área dos lagos analisados, e grupo pertencente sendo estes: proglacial, menores e Drake. Essa divisão dos lagos em grupos é fundamental para analisar a influência exercida por cada uma das variáveis climatológicas: temperatura média do ar, precipitação, velocidade e direção do vento.

\begin{tabular}{c|c|c}
\hline Lagos & Área $\left.\mathbf{( m}^{\mathbf{2}}\right)$ & Grupo \\
\hline $\mathbf{1}$ & 18101 & Proglacial \\
\hline $\mathbf{2}$ & 9053 & Proglacial \\
\hline $\mathbf{3}$ & 7193 & Menores \\
\hline $\mathbf{4}$ & 3957 & Menores \\
\hline $\mathbf{5}$ & 5773 & Proglacial \\
\hline $\mathbf{6}$ & 4476 & Menores \\
\hline $\mathbf{7}$ & 5175 & Menores \\
\hline $\mathbf{8}$ & 12488 & Proglacial \\
\hline $\mathbf{9}$ & 4497 & Menores \\
\hline $\mathbf{1 0}$ & 33271 & Drake \\
\hline $\mathbf{1 1}$ & 18423 & Drake \\
\hline $\mathbf{1 2}$ & 2333 & Drake \\
\hline $\mathbf{1 3}$ & 3417 & Drake \\
\hline $\mathbf{1 4}$ & 2281 & Drake \\
\hline $\mathbf{1 5}$ & 12309 & Drake \\
\hline
\end{tabular}

- Proglacial (Figura 5): O lago 1 (área de 18101 $\mathrm{m}^{2}$ ) foi o que apresentou maior período de tempo com superfície líquida $(01 / 02 / 2011$ e 08/04/2011), apresentando variações no período, sendo que em 23 de fevereiro e 28 de março a cobertura de gelo foi de $100 \%$; o lago 2 com área 


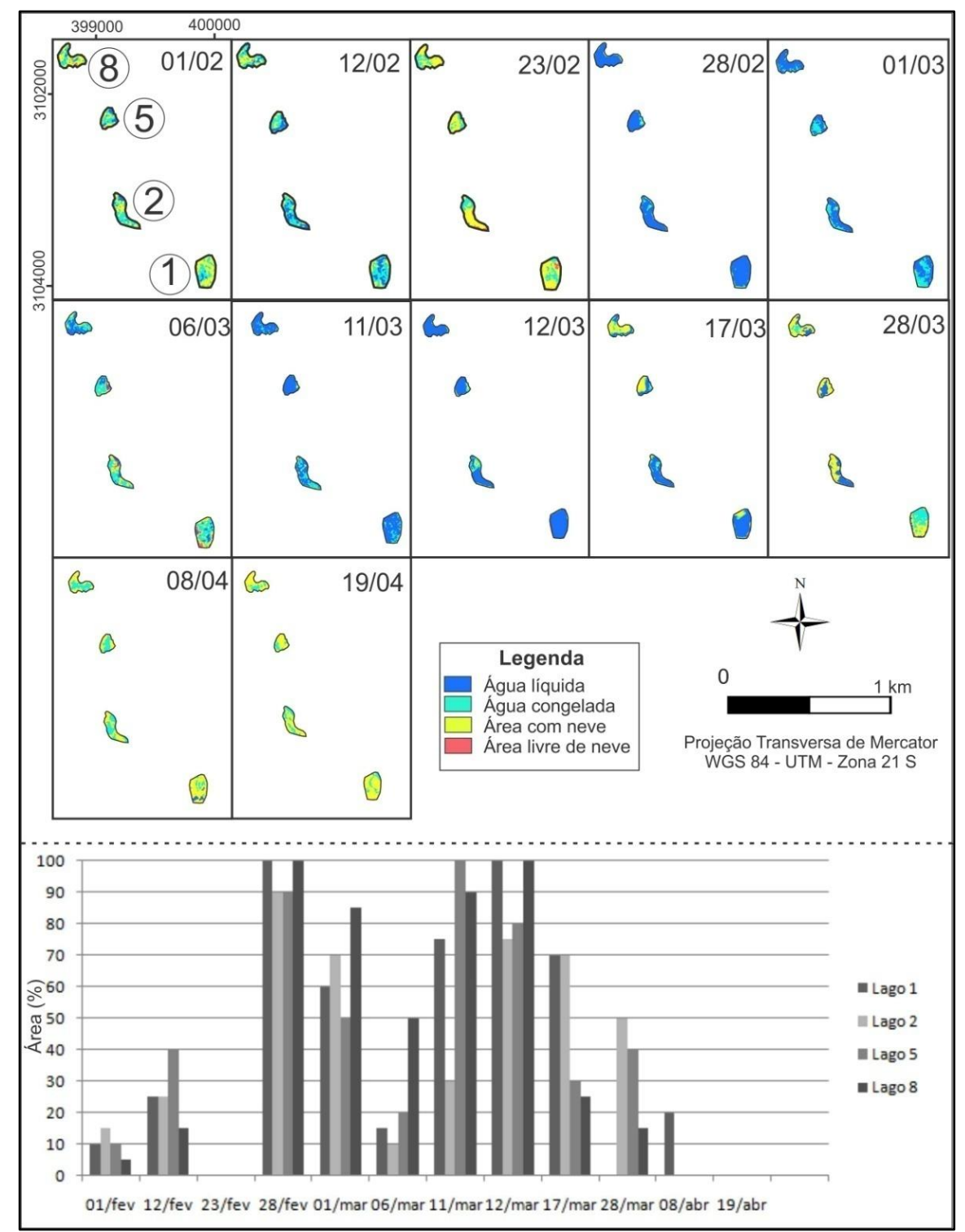

Figura 5 - Lagos proglaciais da geleira Collins. Em 28 de fevereiro todos lagos atingem a área máxima de superfície de água líquida.

de $9053 \mathrm{~m}^{2}$, apresentou superfície líquida entre 1 de fevereiro e 28 de março; para o lago 5 (área de $5773 \mathrm{~m}^{2}$ ) entre 1 de fevereiro e 28 de março houve superfície líquida e somente em 23 de fevereiro teve toda área congelada; o lago 8, área de $12488 \mathrm{~m}^{2}$, ficou entre $1 \mathrm{de}$ fevereiro e 28 de março com superfície líquida, mas também sofreu variações na cobertura.

- Lagos menores - área central da zona proglacial (Figura 6): Lagos 3, 4, 6, 7 e 9 são os menores da área de estudo $(7193,3957$, $4476,5175,4497 \mathrm{~m}^{2}$, respectivamente) e tiveram diferentes data de descongelamento e congelamento total: entre 1 de fevereiro e 28 de março; 12 de fevereiro e 17 de março; 1 de fevereiro e 17 de março; 1 de fevereiro e 8 de abril; e 12 de fevereiro e 8 de abril, respectivamente. Em 23 de fevereiro todos os lagos apresentaram a superfície congelada.
- Lagos voltados para a passagem de Drake (Figura 7): O lago 10, área de $33271 \mathrm{~m}^{2}$, permaneceu com área líquida entre 01 de fevereiro e 8 de abril; os lagos 11 e 15 (área de 18423 e 12309 $\mathrm{m}^{2}$, respectivamente) apresentaram água líquida na superfície entre 01 de fevereiro e 28 de março; os lagos 12, 13 e 14 são os menores do grupo Drake $\left(2333,3417,2281 \mathrm{~m}^{2}\right.$, respectivamente) e permaneceram expostos entre 01 de fevereiro e 17 de março. Em 23 de fevereiro todos os lagos tiveram a superfície congelada.

\section{Estatística de Correlação da Superfície} Líquida dos Lagos X Variáveis Climatológicas

Os valores de Kolmogorov-Smirnov $\mathrm{Z}$ para a variável temperatura variaram entre 1.70 (lagos 6, 12,13 e 14) e 2.13 (lago 7), enquanto que para o $\rho$ -valor todos ficaram abaixo de 0.05 , caracterizando dados não paramétricos. Para a variável de precipitação os valores de Kolmogorov-Smirnov Z 


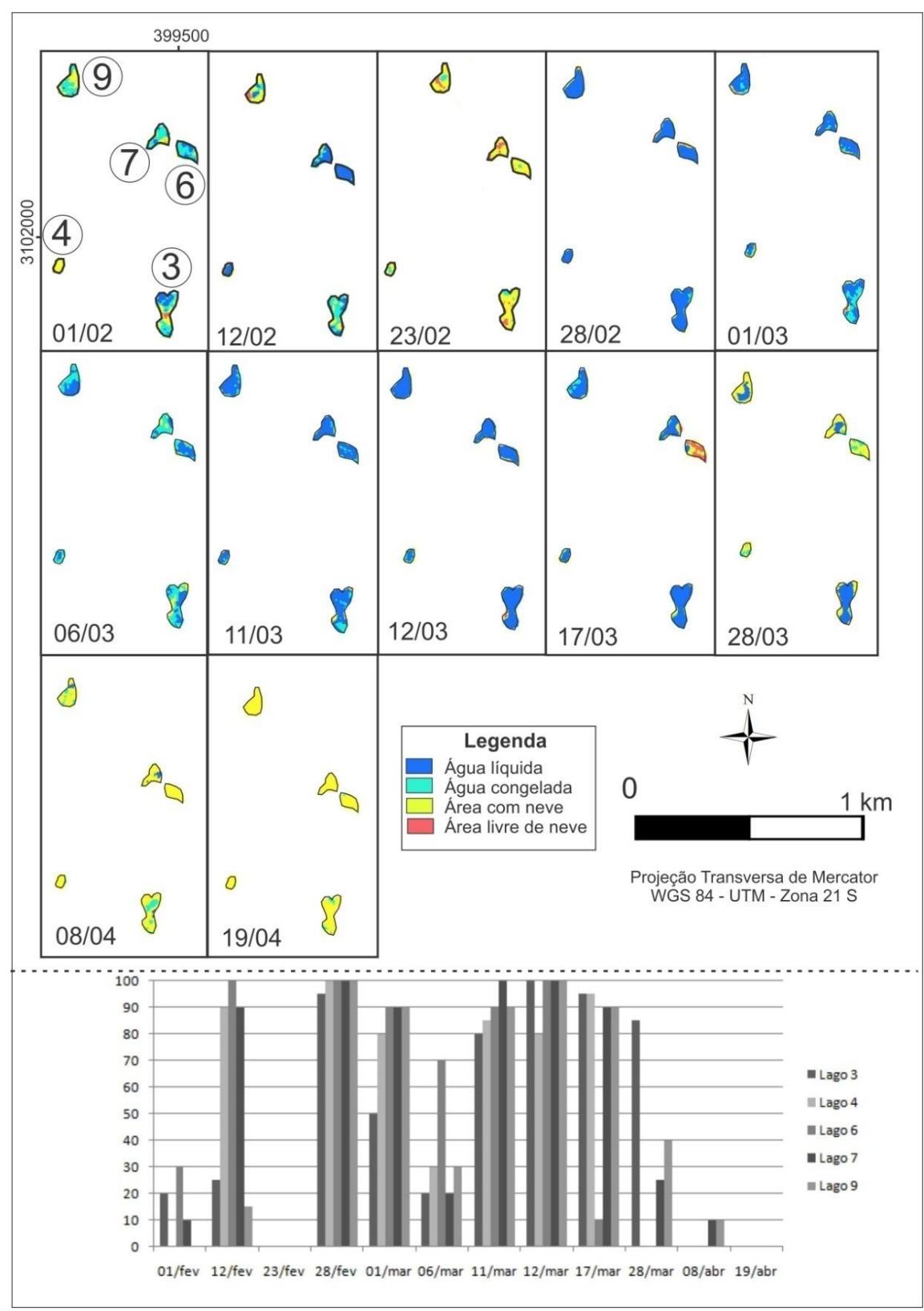

Figura 6 - Lagos (classe "menores" da tabela 8) da porção central da área proglacial. Em 28 de fevereiro todos lagos atingem a área máxima de superfície líquida, voltando a congelar em alguns pontos no dia 06 de março de 2011.

apresentaram valores entre 1.06 e 1.49 e o $\rho$-valor variou entre 0.02 (lago 15) e 0.21 (lagos 1,2 e 8 ). Sendo assim, somente o lago 15 apresentou um valor não paramétrico; para a variável velocidade do vento os valores de Kolmogorov-Smirnov Z permaneceram entre 1.27 (lagos $1,8,11,12,13 \mathrm{e}$ 14) e 1.49 (demais lagos) e o $\rho$-valor foi de 0.07 (lagos $1,8,11,12,13$ e 14) constituindo dados normais e nos demais lagos o valor foi 0.02 sendo considerados assim dados não paramétricos; para a variável direção do vento o Kolmogorov-Smirnov $\mathrm{Z}$ foi de 2.34 para todos os lagos e $\mathrm{o} \rho$-valor foi 0 caracterizando dados não paramétricos (Tabela 4).

Correlação da Superfície Líquida com as Variáveis Climatológicas

- Correlação com a temperatura do ar: Todos os lagos voltados para a passagem de Drake apresentaram correlação acima de 0,40 entre essas duas variáveis: $0,55,0,46,0,54,0,46,0,56$, $0,50,0,60$ (Tabela 5) para os lagos $8,10,11,12$, 13, 14 e 15, respectivamente;

- Correlação com a precipitação: Onze lagos apresentam correlação significativa entre a superfície líquida e a precipitação variando entre 0,51 e 0,65 (Figura 2). Os maiores lagos mostram maior correlação com a variável precipitação com valores de $0,51,0,65,0,58$ e 0,58 para os lagos 1 , 8,10 e 11 , respectivamente. Os únicos lagos que não apresentaram correlação significativa para a variação em precipitação foram o 3, 4, 7 e 12, caracterizados como lagos de menor área $\left(7193 \mathrm{~m}^{2}, 3957\right.$ $\mathrm{m}^{2}, 5175 \mathrm{~m}^{2}$ e $2333 \mathrm{~m}^{2}$, respectivamente), sendo que os lagos 3, 4 e 7 não respondem significativamente a nenhuma variável das analisadas; 


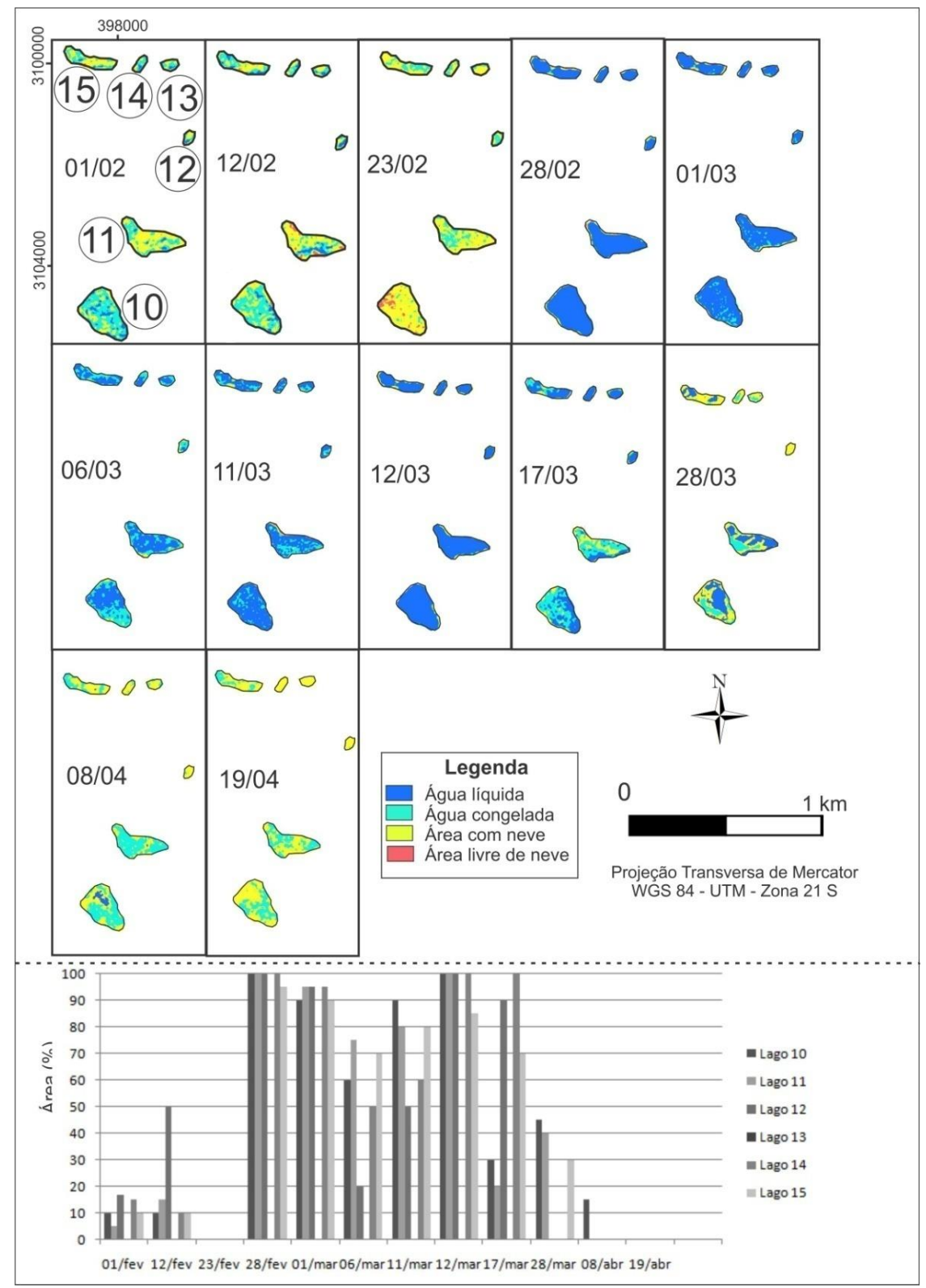

Figura 7 - Lagos voltados para a passagem de Drake. Os lagos atingem o máximo de área de superfície líquida em 28 de fevereiro e congelam totalmente em 23 de fevereiro e 19 de abril de 2011.

Tabela 4 - Valores de Kolmogorov-Smirnov Z e $\rho$ para as variáveis de temperatura, precipitação, velocidade do vento e direção do vento. Valores de significância $(\rho)$ maiores que 0,05 indicam dados normais.

\begin{tabular}{|c|c|c|c|c|c|c|c|c|}
\hline & \multicolumn{2}{|c|}{ Temperatura } & \multicolumn{2}{|c|}{ Precipitação } & \multicolumn{2}{|c|}{ Velocidade do vento } & \multicolumn{2}{|c|}{ Direção do vento } \\
\hline Lago & $\begin{array}{c}\text { Kolmogorov- } \\
\text { Smirnov Z }\end{array}$ & $\rho$-valor & $\begin{array}{c}\text { Kolmogorov- } \\
\text { Smirnov Z } \\
\end{array}$ & $\rho$-valor & $\begin{array}{c}\text { Kolmogorov- } \\
\text { Smirnov Z }\end{array}$ & $\rho$-valor & $\begin{array}{c}\text { Kolmogorov- } \\
\text { Smirnov Z }\end{array}$ & $\rho$-valor \\
\hline 1 & 1.91 & 0.0007 & 1.06 & 0.21 & 1.27 & 0.07 & 2.34 & 0 \\
\hline 2 & 1.91 & 0.0007 & 1.06 & 0.21 & 1.49 & 0.02 & 2.34 & 0 \\
\hline 3 & 1.91 & 0.0007 & 1.27 & 0.07 & 1.49 & 0,02 & 2,34 & 0 \\
\hline 4 & 1.49 & 0.0207 & 1.27 & 0.07 & 1.49 & 0.02 & 2.34 & 0 \\
\hline 5 & 1.91 & 0.0007 & 1.27 & 0.07 & 1.49 & 0.02 & 2.34 & 0 \\
\hline 6 & 1.70 & 0.0040 & 1.27 & 0.07 & 1.49 & 0.02 & 2.34 & 0 \\
\hline 7 & 2.13 & 0.0001 & 1.27 & 0.07 & 1.49 & 0.02 & 2.34 & 0 \\
\hline 8 & 1.91 & 0.0007 & 1.06 & 0.21 & 1.27 & 0.07 & 2.34 & 0 \\
\hline 9 & 1.91 & 0.0007 & 1.27 & 0.07 & 1.49 & 0.02 & 2.34 & 0 \\
\hline 10 & 2.13 & 0.0001 & 1.27 & 0.07 & 1.49 & 0.02 & 2.34 & 0 \\
\hline 11 & 1.91 & 0.0007 & 1.27 & 0.07 & 1.27 & 0.07 & 2.34 & 0 \\
\hline 12 & 1.70 & 0.0044 & 1.27 & 0.07 & 1.27 & 0.07 & 2.34 & 0 \\
\hline 13 & 1.70 & 0.0044 & 1.27 & 0.07 & 1.27 & 0.07 & 2.34 & 0 \\
\hline 14 & 1.70 & 0.0044 & 1.27 & 0.07 & 1.27 & 0.07 & 2.34 & 0 \\
\hline 15 & 1.91 & 0.0007 & 1.49 & 0.02 & 1.49 & 0.02 & 2.34 & 0 \\
\hline
\end{tabular}


- Correlaçãa com o vento (direção $e$ intensidade): Os lagos voltados para a passagem de Drake mostram correlação significativa para a direção do vento apresentando valores de $0,40,0,48,0,55,0,57$ e 0,46 para os lagos $11,12,13,14$ e 15 , respectivamente. O lago 8, apesar de ser proglacial e ter aporte de água de degelo, também está recebendo influência direta dos ventos quentes e úmidos que provêm do mar.

Os lagos 8, 10 e 11 também apresentaram correlação positiva entre a superfície líquida e com a velocidade do vento com valores de 0,45 , 0,5 e 0,51 , respectivamente (Tabela 5).

Tabela 5 - Índice de correlação entre a área líquida dos lagos x temperatura, precipitação e ventos (D-direção e Vvelocidade). Em negrito estão os valores com correlação significativa.

\begin{tabular}{c|c|c|c|c}
\hline & $\begin{array}{c}\text { Correlação da } \\
\text { superficie líquida } \\
\text { temperatura }\end{array}$ & $\begin{array}{c}\text { Correlação da } \\
\text { superficie líquida } \mathbf{x} \\
\text { precipitação }\end{array}$ & $\begin{array}{c}\text { Correlação da } \\
\text { superficie líquida } x \\
\text { vento (V) }\end{array}$ & $\begin{array}{c}\text { Correlação da } \\
\text { superficie líquida x } \\
\text { vento (D) }\end{array}$ \\
\hline Lago 1 & 0,27 & $\mathbf{0 , 5 1}$ & 0,17 & 0,37 \\
\hline Lago 2 & 0,23 & $\mathbf{0 , 5 1}$ & $-0,14$ & 0,22 \\
\hline Lago 3 & 0,09 & 0,27 & $-0,14$ & 0,22 \\
\hline Lago 4 & 0,32 & 0,35 & $-0,17$ & 0,34 \\
\hline Lago 5 & 0,3 & $\mathbf{0 , 5 5}$ & 0,14 & 0,26 \\
\hline Lago 6 & 0,37 & $\mathbf{0 , 5 9}$ & 0,05 & 0,27 \\
\hline Lago 7 & 0,24 & 0,38 & 0,1 & 0,3 \\
\hline Lago 8 & $\mathbf{0 , 5 5}$ & $\mathbf{0 , 6 5}$ & $\mathbf{0 , 4 5}$ & $\mathbf{0 , 4 8}$ \\
\hline Lago 9 & 0,35 & $\mathbf{0 , 4 3}$ & 0,19 & 0,38 \\
\hline Lago 10 & $\mathbf{0 , 4 6}$ & $\mathbf{0 , 5 8}$ & $\mathbf{0 , 5}$ & 0,33 \\
\hline Lago 11 & $\mathbf{0 , 5 4}$ & $\mathbf{0 , 5 8}$ & $\mathbf{0 , 5 1}$ & $\mathbf{0 , 4}$ \\
\hline Lago 12 & $\mathbf{0 , 4 6}$ & 0,35 & $-0,07$ & $\mathbf{0 , 4 8}$ \\
\hline Lago 13 & $\mathbf{0 , 5 6}$ & $\mathbf{0 , 4 3}$ & 0,09 & $\mathbf{0 , 5 5}$ \\
\hline Lago 14 & $\mathbf{0 , 5}$ & $\mathbf{0 , 4 7}$ & 0,08 & $\mathbf{0 , 5 7}$ \\
\hline Lago 15 & $\mathbf{0 , 6}$ & $\mathbf{0 , 5 5}$ & 0,2 & $\mathbf{0 , 4 6}$ \\
\hline
\end{tabular}

\section{DISCUSSÃO}

\section{Parâmetros Climáticos}

Dias com Temperatura Positiva - Dias de Ablação

É possível verificar uma variabilidade, com uma diminuição de dias de ablação para o mês de abril (12, 8, 10 e 4), nas décadas de 1977-1987, 1987-1997, 1997-2007, 2007-2017.

Considerando as médias históricas de dias de temperatura positiva de 2011, os meses de janeiro, fevereiro, março estão dentro da média de 2007-2017, e somente o mês de abril está abaixo da média. É importante salientar que a variabilidade climática e as mudanças climáticas durante todo o ano podem afetar os lagos pela mudança de energia (por exemplo, radiação solar, calor atmosférico e fricção do vento) e entradas de material (por exemplo, precipitação, partículas em suspensão e substâncias dissolvidas) e também alterando as características temporais e espaciais dessas entradas (Pham et al., 2008).

Dessa forma, a ablação e descongelamento da superfície do lago estão ligadas a toda troca de matéria e energia que ocorre nas demais estações sazonais.

\section{Temperatura Média do Verão}

Ainda que o ano de 2011 demonstre o número de dias com temperaturas positivas dentro do padrão para a década de 2007-2017, a temperatura média para o mês de fevereiro é superior à média $\mathrm{e}$ para o mês de março é inferior. Essa diminuição da temperatura média pode estar ligada a tendência de resfriamento na Península Antártica (PA).

A maioria dos dados das estações meteorológicas da PA revelam um resfriamento notável para a década 2006-2015, maior no norte da PA (Oliva et al., 2017). Contudo, essa tendência de diminuição da temperatura média do ar pode também afetar o período da duração da estação de ablação. Dessa forma, pode-se verificar maiores mudanças nos parâmetros calculados para os meses de março e abril.

\section{Estação de Ablaçãa}

O ano de 2011, apresenta uma estação de ablação diferente do padrão observado em outros anos, com somente 90 dias. Uma situação atípica 
que pode ser explicada pelo período de mudança nos padrões de ventos, que geralmente ocorrem em abril, e nesse ano ocorreu em março.

Os ventos $\mathrm{NO}$ e $\mathrm{O}$ são mais frequentes, alcançam as velocidades mais altas e são relativamente quentes. Em fevereiro, eles são mais comuns, trazendo fortes precipitações, umidade relativa e cobertura de nuvens (RakusaSuszczewski et al. 1993). Assim que ocorreu a mudança no padrão de vento, em 17 e março, logo em seguida (19 de março) o período de ablação cessou.

\section{Lagos Classificados com as Imagens TSX}

Diante da escassez de imagens ópticas sem cobertura de nuvens para a península Fildes, as imagens TSX demonstraram resultados ainda não alcançados para o monitoramento temporal da área de estudo, bem como uma análise inédita da fenologia dos lagos. De forma geral, foi possível observar em campo que o ambiente é muito dinâmico, e a superfície pode congelar e descongelar em questão de horas para alguns lagos com menores áreas.

Os lagos com maior área demonstraram menor variabilidade na superfície de congelamento/ descongelamento, o que se deve a presença de maior volume de água e trocas de energia com o ambiente. Já os lagos proglaciais, que apresentam entrada de água no seu sistema proveniente de derretimento da geleira, apresentam uma quebra mais rápida da superfície do gelo.

A data de 28 de fevereiro foi considerada como o dia em que todos os lagos apresentavam superfície líquida, contudo esse descongelamento total pode ter ocorrido em algum momento entre 23 e 28 fevereiro, já que não há imagens para esse período.

Em 12 de março ainda permaneciam todos os lagos descongelados apesar de haver algumas áreas já congeladas nesse período, e em 08 de abril todas as superfícies já estavam congeladas. Salienta-se que a detecção de água líquida também pode ser difícil com imagens de radar quando a superfície do lago possui neve, gelo e água (Hall et al., 1994).

Nos dias com maior quantidade de neve acumulada, os resultados da classificação se apresentaram inferiores com maior confusão entre os pixels.

\section{Correlação com a Temperatura do Ar}

Dentre os lagos analisados, 7 dos 15 apresentaram correlação significativa entre $o$ aumento da temperatura média do ar e a expansão da superfície líquida dos lagos. Todos os lagos voltados para a passagem de Drake apresentaram correlação significativa.

Isso pode ser explicado pela exposição a ventos mais aquecidos e úmidos que provêm da passagem de Drake que acabam influenciando na quebra e derretimento do gelo superficial dos lagos. É possível observar que quando os ventos provenientes do Drake trocam sua direção (de $\mathrm{NO}$ e O para SE), a superfície dos lagos congela logo em seguida, ou seja, com os ventos não mais influenciando os lagos, provavelmente outros fatores passam a atuar na dinâmica fenológica.

A morfometria do lago também deve ser considerada, pois será um determinante da cobertura de gelo, e isso afeta a incidência do vento, a circulação e a temperatura da água, bem como o armazenamento de calor (Jeffries \& Morris, 2005).

\section{Correlação com a Precipitação}

A resposta da dinâmica de congelamento e descongelamento da superfície dos lagos à precipitação foi confirmada pela correlação positiva em 11 dos 15 lagos. Os efeitos da precipitação líquida nesses sistemas, ocasionam o aumento do processo de fusão da neve (devido a liberação de calor latente quando a água da chuva congela) e ocorre um aumento da quantidade de água líquida no sistema glacio fluvial, que além de aumentar o nível dos lagos pode influenciar nos processos de troca de energia nas camadas dos lagos.

A queda de neve, associada a uma temperatura menor que $0^{\circ} \mathrm{C}$, ocasiona congelamento dos canais glacio fluviais, cessando a fusão da neve, com diminuição da quantidade de água líquida que chega aos lagos e, consequentemente, diminuindo as trocas de energia.

Os lagos 3, 4 e 7 não respondem significativamente a nenhuma das variáveis analisadas. Isso pode ser explicado por algum fator local que afete diretamente a fenologia do sistema hidrológico.

Segundo Livingstone (1997), a espessura e condições de uma camada de gelo cobrindo um lago dependem de muitos processos, envolvendo diversas variáveis ambientais que são frequentemente difíceis de mensurar porque demandaria medição durante todo verão antártico.

\section{Correlação com o Vento (Direção e Intensidade)}

A mudança na direção dos ventos (conforme explicado no item 5.1.3) afeta diretamente a resposta de superfície dos lagos voltados para a 
passagem de Drake e é responsável pelo fim da estação de ablação para a Fildes. Como um trabalho futuro, pode-se avaliar como ocorre o comportamento (direção e velocidade) do vento na série histórica 1977-2017.

Por fim, salienta-se a importância de desenvolver estudos sobre a fenologia dos lagos das áreas livres de gelo da Antártica, buscando futuramente estabelecer padrões para as datas de congelamento e quebra de gelo da superfície.

Muitos autores já demonstram como esse dado é um importante indicador de variações climáticas e mudanças climáticas globais (Magnuson et al., 2000; Assel et al., 2003).

\section{CONSIDERAÇÕES FINAIS}

A correlação de temperatura do ar atmosférico com a área demonstra padrão de correlação significativa em 7 dos 15 lagos (usando a área obtida com a classificação das imagens TSX). Em outros trabalhos a variável de temperatura era a de maior correlação, contudo para esta pesquisa a precipitação se mostrou como uma importante variável na formação da superfície líquida.

Os únicos lagos que não responderam significativamente para a precipitação foram os 3, 4, 7 e 12, caracterizados como lagos de área reduzida $\left(7193 \mathrm{~m}^{2}, 3957 \mathrm{~m}^{2}, 5175 \mathrm{~m}^{2}\right.$ e $2333 \mathrm{~m}^{2}$, respectivamente), e que podem ter a fenologia ligada à profundidade e volume de água.

Os lagos 3, 4 e 7 não respondem significativamente a nenhuma variável das analisadas, ou seja, nesse caso seria necessário considerar outras variáveis como radiação, fluxo de água para o sistema, temperatura do solo, etc.

Para os lagos proglaciais com conexão com a geleira, por canais de degelo, observa-se que a dinâmica de entrada de água provoca uma quebra do gelo mais rápida na superfície, na porção a montante.

Os lagos voltados para a passagem de Drake mostram correlação significativa para a direção do vento apresentando correlações de 0,40, 0,48, $0,55,0,57$ e 0,46 para os lagos $11,12,13,14$ e 15. É possível que o vento atue causando ondas na superfície líquida e que por sua vez, provocam a quebra do gelo na superfície.

Para a velocidade do vento só foi observado correlação em três lagos, estando todos próximos a passagem de Drake.

Quanto à direção dos ventos, esta variável pode estar ligada à mudanças no período da estação de ablação para a península Fildes.
Entre 28 de janeiro e 17 de março, houve um predomínio de ventos provenientes de $\mathrm{N}, \mathrm{O}$ e $\mathrm{NO}$ e a partir dessa data houve mudança no comportamento e apresentaram-se, na sua maioria, como sendo de SE.

A estação de ablação termina exatamente dois dias após a mudanças de direção dos ventos, em 19 de março. Já que a península Fildes é cercada pelo oceano em grande parte, a influência desse sistema é fundamental e controla o microclima local.

Após, essa data a resposta de superfície dos lagos varia seguindo provavelmente outros fatores como a morfometria dos lagos.

As imagens TSX permitiram um detalhamento temporal inédito para a área de estudo possibilitando mapear os lagos no período de fevereiro até abril de 2011. A resolução espacial de 1 e $3 \mathrm{~m}$ permitiu também a classificação de lagos com menores áreas e boa acurácia na distinção dos alvos delimitados.

Por fim, no ano de 2011, analisado pelas imagens de radar, o número de dias com temperatura positiva esteve no padrão para a década de 2007-2017, porém a temperatura média para o mês de fevereiro foi superior à média e para o mês de março foi inferior.

Quanto à estação de ablação, apresentou uma situação atípica que pode ser explicada pelo período de mudança nos padrões de ventos, que geralmente ocorrem em abril, e naquele ano ocorreu em março.

A tendência de diminuição da temperatura média do ar para a PA pode também afetar o período da duração da estação de ablação. Dessa forma, pode-se verificar maiores mudanças nos parâmetros calculados para os meses de março e abril.

\section{AGRADECIMENTOS}

À FAPERGS, CAPES e CNPq pelo auxílio financeiro. Ao professor Matthias H. Braun por disponibilizar as imagens TSX.

\section{REFERÊNCIAS}

ADRIAN, R.; O'REILLY, C. M.; ZAGARESE, H.; BAINES, S. B.; HESSEN, D. O.; KELLER, W.; VAN DONK, E. Lakes as sentinels of climate change. Limnological and

Oceanography, n. 54, n. 6, p. 2283-2297, 2009

AIRBUSDS, TerraSAR-X: Image Product Guide. Disp. em: http://www.intelligence-airbusds.com/files/pmedia/public/r4 
59_9_20171004_tsxx-airbusds-ma-0009_tsx-productguide i2.01.pdf. Acesso em 20 de outubro de 2017.

ASSEL, R.; CRONK, K.; NORTON, D. Recent trends in Laurentian Great Lakes ice cover. Climatic Change, n. 57, p 185-204, 2003.

AUSTIN, J.A. \& COLMAN, S.M. Lake Superior summer water temperatures are increasing more rapidly than regional air temperatures: A positive ice-albedo feedback. Geophysical Research Letter, n. 34, 2007.

BADURSKA, M. Orthorectification and geometric verification of high resolution TerraSAR-X images. Geomatics and Environmental Engineering, v. 5, n. 3, p. 13-25, 2011

BAGHDADI, N.; BERNIER, M.; GAUTHIER, R.; NEESON, I. Evaluation of C-band SAR data for wetlands mapping. International Journal Remote Sensing, v. 22, n. 1, p. 71-88, 2001.

BLENCKNER, T. A conceptual model of climate-related effects on lake ecosystems. Hydrobiologia, n. 53, 2005.

BRADLEY, R.S. \& ENGLAND, J. Recent climatic fluctuations of the Canadian high Arctic and their significance for glaciology. Arctic and Alpine Research, v 10, n. 4, p. 715 $731,1978$.

BRAUN, M.; SAURER, H.; SIMÕES, J.C.; VOGT, S.; GOSSMANN, H. The influence of large scale atmospheric circulation on surface energy balance and ablation on King George Island, Antarctica. International Journal of Climatolology, v. 21, n.1, p. 21-36, 2001

CASTENDYK, D.N.; OBRYK, M.K.; LEIDMAN, S.Z.; GOOSEFF, M.; HAWES, I. Lake Vanda: A sentinel for climate change in the McMurdo Sound Region of Antarctica. Global and Planetary Change, n. 144, p. 213-227, 2016.

DORAN, P.T.; WHARTON JR., R.A.; LYONS, W.B Paleolimnology of the McMurdo Dry Valleys, Antarctica Journal Paleolimatic, n. 10, p. 85-114, 1994.

DUGUAY, C.R. \& LAFLEUR, P.M. Determining depth and ice thickness of shallow sub-Artic lakes using space-borne optical and SAR data. International Journal of Remote Sensing, n. 24, p. 475-489, 1997.

DUGUAY, C.R., PROWSE, T.D., BONSAL, B.R., BROWN R.D., LACROIX, M.P.; MENARD, P. Recent trends in Canadian lake ice cover, Hydrology Processes, n. 20, p. 781801, 2006.

FERRANDO, F.A., VIEIRA R., ROSA K.K. Sobre el calentamiento global en la Isla Rey Jorge: Procesos y evidencias en el Glaciar Wanda y su entorno. Revista Informaciones Geográficas, v. 41, n. 25-40, 2009

GORRAB, A.; ZRIBI, M.; BAHGDABI, N.; MOUGENOT, B.; FANISE, P. Retrieval of both soil moisture and texture using TerraSAR-X images. Remote Sensing, MDPI, p. 1009810116,2015

HALL, D.K.; FAGRE, D.G.; KLASNER, F.; LINEBAUGH, G.; LISTON, G.E. Analysis of ERS 1 synthetic aperture radar data of frozen lakes in northern Montana and implications for climate studies. Journal of Geophysical Research, n. 99, p 22473-22482, 1994.

HANSON, B. Reconstructing mass-balance profiles from climate for an Arctic ice cap. The Physical basis of the ice sheets, IAHS, n. 170, p. 181-189, 1987

JEFFREIS, M. O., MORRIS, K., WEEKS, W. F.; WAKABAYASHI, H. Structural and stratigraphic feature and ERS 1 synthetic aperture radar backscatter characteristics of ice growing on shallow lakes in NW Alaska, winter 1991-1992. Journal of Geophysical Research, n. 99, p. 22459-22471, 1994.

JEFFRIES, M. O.; MORRIS, K.; KOZLENKO, N. Ice characteristics and processes, and remote sensing of frozen rivers and lakes. Remote sensing in northern hydrology, $\mathrm{n}$. 163, 2005.

KROPACEK, J.; MAUSSION, F.; CHEN, F.; HOERZ, S.; HOCHSCHILD, V. Analysis of ice phenology of lakes on the Tibetan Plateau from MODIS data. The Cryosphere, n. 7, p.
287-301, 2013.

LATIFOVIC, R. \& POULIOT, D. Analysis of climate change impacts on lake ice phenology in Canada using the historical satellite data record. Remote Sensing of Environment, n. 106, p. 492-507, 2007.

LIVINGSTONE, D.M. Break-up dates of alpine lakes as proxy data for local and regional mean surface air temperatures. Climatic Change, n. 37, n. 2, p. 407-439, 1997.

MAGNUSON, J.J.; ROBERTSON, D.M.; BENSON, B.J.; WYNNE, R.H.; LIVINGSTONE, D.M.; ARAI, T.; ASSEL, R. A.; BARRY, R.G.; CARD, V.; KUUSISTO, E.; GRANIN, N.G.; PROWSE, T.D.; STEWART, K.M.; VUGLINSKI, V.S. Historical trends in lake and river ice cover in the Northern Hemisphere. Science, n. 289, p. 1743-1746, 2000.

MENARD, P.; DUGUAY, C.R.; FLATO, G.M.; ROUSE, W.R. Simulation of ice phenology on Great Slave Lake, Northwest Territories, Canada. Hydrological Processes, n. 16, p. 36913706, 2002.

MICHEL, R.F.M.; SCHAEFER, C.E.G.R.; LÓPEZMARTÍNEZ, J.; SIMAS, F.N.B.; HAUS, N.W.; SERRANO, E.; BOCKHEIM, J.G. Soils and landforms from Fildes Peninsula and Ardley Island, Maritime Antarctica. Geomorphology, v. 225, p. 76-86, 2014.

NOON, P. E.; LENG, M. J.; ARROWSMITH, C.; EDWORTHY, M. G.; STRACHAN, R. J. Seasonal observations of stable isotope variations in a valley catchment, Signy Island, South Orkney Islands, Antarctic Science, n. 14, p.333-342, 2002.

OLECH, M. Annotated checklist of Antarctic lichens and lichenicolous fungi. Kraków: The Institute of Botany of the Jagiellonian University, 145 p., 2001.

OLIVA, M.; NAVARRO, F.; HRBÁČEK, F.; HERNÁNDEZ, A.; NÝVLT, D.; RUIZ-FERNANDEZ, J.; TRIGO, R. Recent regional climate cooling on the Antarctic Peninsula and associated impacts on the cryosphere. Science of the Total Environment, n. 580, p. 210-223, 2017.

ORHEIM, O. A 200-year record of glacier mass balance at Deception Island, southwest Atlantic Ocean, and its bearing on models of global climatic change. Institute of Polar Studies Report, n. 42, 118 p., 1972.

PALECKI, M.A. \& BARRY, R.G. 'Freeze-Up and Break-Up of Lakes as an Index of Temperature Changes during the Transition Seasons: A Case Study for Finland'. Journal of Climate Applied Meteorology, n. 25, p. 893-902, 1986.

PHAM, S.V.; PETER L.; MCGOWAN, R.; SUZANNE, P.P. Spatial variability of climate and land-use effects on lakes of the northern Great Plains. Journal Limnology and Oceanography, n. 53, n. 2, p. 728-742, 2008.

PIERSON, D.C.; WEYHENMEYER, G.A.; ARVOLA, L.; BENSON, B.; BLENCKNER, T.; KRATZ, T.; LIVINGSTONE, D.M.; MARKENSTEN, H.; MARZEC, G.; PETTERSSON, K.; WEATHERS, K. An automated method to monitor lake ice phenology. Limnology Oceanografic: Methods, n. 9, p. 74-83, 2011.

QUAYLE, W.C.; PECK, L.S.; PEAT, H., ELLIS-EVANS, J.C.; HARRIGAN, P.R. Extreme responses to climate change in Antarctic lakes, Science, n. 295, p. 645, 2002.

QUESADA, V.; KAUP, H. L. Landscape control of high latitude lakes in a changing climate. In: BERGSTROM, D.M. (eds.), Trends in Antarctic Terrestrial and Limnetic, 2006.

RAKUSA-SUSZCZEWSKI S.; MIETUS M.; PIASECKI J. Weather and climate. In: RAKUSA-SUSZCZE-WSKI, S. The maritime Antarctic coastal ecosystem of Admiralty Bay. Varsóvia: Polish Academy of Sciences, p. 19-25, 1993.

ROSA, K.K; MENDES JR, C.W.; ARIGONY-NETO, J.; PETSCH, C.; SIMOES, J.C. Potencial do uso das imagens COSMO-SkyMed na investigação da dinâmica de áreas em ambientes glaciais recentemente expostos, campo de gelo Krakow, ilha Rei George, Antártica. In: SIMPÓSIO BRASILEIRO DE SENSORIAMENTO REMOTO, XVII, São Jose dos Campos. 2015. Anais...São Jose dos Campos: INPE, SIMAS, F., C.; SCHAEFER, M. F. F; DACOSTA, I. Genesis,

São Paulo, UNESP, Geociências, v. 39, n. 2, p. 559 - 572, 2020 
properties and classification of cryosols from admiralty Bay, Maritime Antarctica. Geoderma, v. 144, n. 1-2, p. 116-122, 2008.

ŠMEJKALOVÁ, T.; EDWARDS, M. E.; DASH, J. Artic lakes show strong decadal trend in earlier spring ice-out. Scientific reports. n. 6, p. 38449, 2016.

SMITH, R.C.; STAMMERJOHN, S.E.; BAKER, K. Surface air temperature variations in the western Antarctic Peninsula Region. In: ROSS, R. M.; HOFMANN, E. E.; QUETIN, L. B. (eds.). Foundations for ecological research west of the Antarctic Peninsula. American Geophysical Union, Antarctic Research Book Series, v. 70, p. 105-121, 1996.

TURNER, J. LEONARD, S. Synoptic scale weather systems around the Antarctic Peninsula from satellite imagery and model fields. In: CONFERENCE ON SATELLITE METEOROLOGY AND OCEANOGRAPHY, 8th. Atlanta, 1996. Anais... Atlanta
VAVRUS, S.J., WYNNE, R.H.; FOLEY, J.A. 'Measuring the Sensitivity of Southern Wisconsin Lake Ice to Climate Variations and Lake Depth Using a Numerical Model'. Limnological Oceanography, n.41, n. 5, p. 822-831, 1996.

WILLIAMS, G.P. 'Predicting the Date of Lake Ice Break-Up', Water Resources Research, n. 7, n. 2, p. 323-333, 1971.

WILLIAMSON, C.E.; SAROS, J.E.; VINCENT, W.F.; SMOL, J.P. Lakes and reservoirs as sentinels, integrators, and regulators of climate change. Limnology Oceanography, n. 54, p. 2273-2282, 2009.

Submetido em 3 de outubro de 2019 Aceito para publicação em 28 de abril de 2020 